\title{
Is Nasal Septum Deviation Severity a Significant Factor on Voice in Patients Undergoing Septoplasty?
}

\author{
Süleyman Emre Karakurt, Kürşat Murat Özcan, Aykut İkincioğulları, Mehmet Ali Çetin, Müge Özcan and \\ Hacı Hüseyin Dere \\ Ankara Numune Training and Research Hospital ENT \& HNS Clinic, Hacettepe Mahallesi Talatpaşa Bulvarı No.44 Altındağ, \\ Ankara, Turkey
}

\begin{abstract}
Objective: To determine whether septoplasty is an effective factor on the voice in patients with varying degrees of nasal septum deviation.

Study Design: Descriptive study.

Place and Duration of Study: Ankara Numune Training and Research Hospital, Ear Nose Throat Clinic, Ankara, Turkey, from November 2018 to March 2019.

Methodology: A total of 69 patients formed groups I, II and III. Groups I, II and III consisted of patients with mild, moderate and severe nasal deviation, respectively. All patients underwent septoplasty under general anesthesia. Subjective and objective voice analyses were performed for each patient preoperatively and at the postoperative third month.

Results: There was no statistical difference between the mean pre- and postoperative voice handicap index-30 (VHI-30) scores in group I and group II. Postoperative mean VHI-30 scores were significantly lower in group III. In groups I and II, the differences between the mean pre- and postoperative fundamental frequency (F0), frequency perturbation (jitter), amplitude perturbation (shimmer) and noise-to-harmonics ratio (NHR) values were not statistically significant. While the differences between the mean preoperative and postoperative F0, jitter and NHR values in group III were not statistically significant, mean postoperative shimmer value was lower than preoperative one with significantly difference.

Conclusion: Septoplasty affects the voice positively in patients having severe septum deviation.
\end{abstract}

Key Words: Septoplasty, Voice, Acoustic, Nasal septum, Analysis.

How to cite this article: Karakurt SE, Özcan KM, İkincioğulları A, Çetin MA, Özcan M, Dere HH. Is nasal septum deviation severity a significant factor on voice in patients undergoing septoplasty? J Coll Physicians Surg Pak 2020; 30(3):287-291.

\section{INTRODUCTION}

Nasal obstruction is a symptom frequently encountered by otolaryngologists in daily practice and significantly affects quality of life. Nasal septum deviation is the most common cause of nasal obstruction. ${ }^{1}$ Treatment of nasal septum deviation is surgical and septoplasty is a welldefined procedure for nasal septum deviation. ${ }^{2,3}$

Nasal obstruction can significantly affect the voice. ${ }^{4}$ It has been suggested that obstruction at any level of the upper airway affects articulation and voice resonance. ${ }^{5,6}$ From this perspective, not only the degree of nasal obstruction but also the septoplasty procedure, which is performed to resolve the obstruction, may be hypothesised to have significant influences on voice. There are investigations examining the effects of septoplasty on sound in some of which septoplasty has been reported to be an effective factor on sound, while others have achieved opposing results. ${ }^{4,5,7,8}$

Correspondence to: Dr. Süleyman Emre Karakurt, Ankara Numune Training and Research Hospital ENT \& HNS Clinic, Hacettepe Mahallesi Talatpaşa Bulvarı No:44 Altındăg, Ankara-Turkey

E-mail: suleymanemrekarakurt@gmail.com

Received: November 25, 2019; Revised: February 15, 2020;

Accepted: February 15, 2020
There is a lack of a widely used classification system for septum deviation severity, which may lead to heterogeneity in the studied patient groups; thus the conflicting results. Various septum deviation classification systems have been previously described. ${ }^{9-11}$ By using the classification system proposed by Vidigal et al. ${ }^{9}$, which stands out with its practicality among the others, the authors aimed to prevent the heterogeneity mentioned above. The purpose of this research was to examine the effects of septoplasty on voice in patient groups formed on the basis of nasal septum deviation severity, and to investigate whether the degree of deviation is an effective factor on the voice in patients undergoing septoplasty.

\section{METHODOLOGY}

The study was conducted from November 2018 to March 2019 following the approval by the institutional Ethical Review Board. Patients were informed of the study purpose and their signed consents were taken. Sixty-nine patients with nasal obstruction, who had nasal septum deviation as diagnosed by otolaryngological examination including panendoscopic evaluation, were admitted in the research. Smokers, patients undergoing 
sinonasal surgery, patients with an additional sinonasal disease accompanying septum deviation, and patients with a known voice disorder were excluded. Patients who met the inclusion criteria were seperated into three groups consistent with the categorisation system proposed by Vidigal et al., ${ }^{9}$ such that group I included patients in whom septal deviation did not reach the lower nasal turbinate; group II had those with septal deviation reaching the lower nasal turbinate; and group III consisted of patients with septal deviation reaching the lateral wall and compressing the lower nasal turbinate. All patients underwent septoplasty under general anesthesia.

In order to evaluate the subjective effects of their nasal obstruction on quality of life, the nasal obstruction symptom evaluation (NOSE) scale survey was completed by each patient preoperatively and at third postoperative month. The NOSE scale is a validated questionnaire that evaluates the extent to which five different nasal obstruction-related items impact on the patient. ${ }^{12}$ Higher scores are associated with more severe problems.

For subjective analysis of voice, the voice handicap index-30 (VHI-30) questionnaire was completed by each patient preoperatively and 3 months after the operation. $\mathrm{VHI}-30$ is a survey which is used to judge the grade of vocal impairment in individuals' ordinary life.$^{13}$ Each item in this survey has score between 0 and 4 points. Higher scores are associated with a more severe subjective vocal impairment.

Sound study was performed in an isolated room, free of environmental noise. Voice recordings were performed with an Audio-Technica-AT2005 microphone (AudioTechnica Productions, Western Hemisphere). Patients were asked to sit in front of the microphone such that their mouth was at $15 \mathrm{~cm}$ away from the microphone. They were then asked to articulate the letter /a/ for 5 seconds and then the word /mana/ which contains the nasal consonants $/ \mathrm{m} /$ and $/ \mathrm{n} /$ and the nasalised vowel /a/ again for 5 seconds. Acoustical evalutions were performed with Praat software (Paul Boersma, 2001. Version 6.017, available online at http://www.praat.org/). The vowel /a/ recordings were used to evaluate the average $\mathrm{F} 0$, jitter, shimmer, and noise-to-harmonics ratio (NHR) while the word /mana/ recordings were utilised for F1, F2, F3 and F4 analysis. Whole-voice recordings were repeated preoperatively and at $3^{\text {rd }}$ month postoperatively.

Intragroup comparisons of pre- and postoperative mean NOSE scores, VHI-30 scores, F0, jitter, shimmer, NHR and F1, F2, F3, and F4 parameters were performed.

Quantitative data were presented as mean \pm S.D. or median (IQR). Qualitative data were presented as frequency and percentage. The Shapiro-Wilk test was used to assess the distribution of data. Differences between dependent groups were analysed using the paired T-test or Wilcoxon signed-rank test. $\mathrm{P}<.05$ values were deemed statistically significant. SPSS statistical software (SPSS for Windows version 21.0; SPSS Inc., Chicago, IL, USA) was utilised for whole statistical calculations.

\section{RESULTS}

Of the 69 patients, 27 belonged to group I, 22 to group $\mathrm{II}$, and 20 to group III. Fifteen $(21.7 \%)$ patients were females and $54(78.3 \%)$ were males. The mean age of the patients was $32.1 \pm 11$ years (range: $18-57$ years). Group I composed of 7 (25.9\%) women and 20 (74.1\%) men; group II composed of $4(18.2 \%)$ women and 18 $(81.8 \%)$ men; group III composed of $4(20 \%)$ women

Table I: Pre- and postoperative voice analysis results of the groups, and statistical evaluation of the nose scores.

\begin{tabular}{|c|c|c|c|}
\hline & Preoperative & Postoperative & $p$-value \\
\hline \multicolumn{4}{|l|}{ Group I } \\
\hline VHI-30 & $8.19 \pm 3.29$ & $7.74 \pm 3.16$ & .247 \\
\hline F0 & $143.8(45.7)$ & 145.4 (38.6) & .113 \\
\hline Jitter (\%) & $0.42(0.51)$ & $0.40(0.36)$ & .159 \\
\hline Shimmer s(\%) & $2.40(1.06)$ & $2.40(1.11)$ & .182 \\
\hline NHR & $0.050(0.06)$ & $0.060(0.04)$ & .955 \\
\hline NS & $11.00(6)$ & $1(3)$ & $<.001$ \\
\hline \multicolumn{4}{|l|}{ Group II } \\
\hline VHI-30 & $9.86 \pm 4.07$ & $9.45 \pm 3.98$ & .316 \\
\hline $\mathrm{FO}$ & $143.9(34)$ & $138.8(51)$ & .2 \\
\hline Jitter (\%) & $0.33(0.36)$ & $0.31(0.36)$ & .613 \\
\hline Shimmer (\%) & $2.68 \pm 0.88$ & $2.6 \pm 0.83$ & .175 \\
\hline NHR & $0.050(0.06)$ & $0.060(0.04)$ & .186 \\
\hline NS & $13.50(5.75)$ & $1.5(3)$ & $<.001$ \\
\hline \multicolumn{4}{|l|}{ Group III } \\
\hline VHI-30 & $12(8)$ & $10(2.85)$ & $<.001$ \\
\hline $\mathrm{FO}$ & $149.9(52.7)$ & $143.1(50.9)$ & .104 \\
\hline Jitter (\%) & $0.39(0.51)$ & $0.36(0.47)$ & .27 \\
\hline Shimmer (\%) & $2.94 \pm 0.63$ & $2.54 \pm 0.63$ & .003 \\
\hline NHR & $0.04(0.04)$ & $0.04(0.05)$ & .416 \\
\hline NS & $15(6.75)$ & $1(2.75)$ & $<.001$ \\
\hline
\end{tabular}

Table II: Statistical analysis of preoperative and postoperative /mana/ word's voice analysis results of groups.

\begin{tabular}{cccc}
\hline & Preoperative & Postoperative & P-value \\
\hline Group I & & & \\
F1 & $649.9(106.6)$ & $632.9(63.3)$ & .29 \\
F2 & $1371.4 \pm 153.6$ & $1360.9 \pm 174.2$ & .34 \\
F3 & $2805.5 \pm 159.7$ & $2770.9 \pm 181.9$ & .107 \\
F4 & $3738.8 \pm 280.4$ & $3708.6 \pm 294.2$ & .248 \\
\hline Group II & & & \\
F1 & $610.8 \pm 113.1$ & $600.6 \pm 105.1$ & .411 \\
F2 & $1328.5 \pm 184.5$ & $1312.7 \pm 169.1$ & .408 \\
F3 & $2779.8 \pm 139.9$ & $2749.1 \pm 187.9$ & .204 \\
F4 & $3689.5 \pm 177.9$ & $3675.7 \pm 227.6$ & .488 \\
\hline Group III & & & \\
F1 & $603.4 \pm 119.6$ & $595.1 \pm 121.6$ & .357 \\
F2 & $1299 \pm 167.1$ & $1287.9 \pm 169.9$ & .396 \\
F3 & $2697(346.8)$ & $2742.6(349.6)$ & .126 \\
F4 & $3776.4(226.8)$ & $3788.3(263.7)$ & .108 \\
\hline
\end{tabular}


and $16(80 \%)$ men. The mean age of the patients in groups I, II and III were $32.4 \pm 10.7,31.7 \pm 11.6$ and 32.1 \pm 11.3 years, respectively. Postoperative mean NOSE scores were statistically significant lower than preoperative NOSE scores in all groups $(p=0.001$, for all groups, Table I). The difference between the pre- and postoperative mean VHI-30 scores in groups I and II was not statistically significant $(p=0.247$ and $p=0.316$, respectively, Table I). In Group III, the postoperative mean $\mathrm{VHI}-30$ score was significantly lower than the preoperative mean score $(p<.001$, Table I). The mean preoperative and postoperative F0, jitter, shimmer and NHR values in group I were found statistically similar. $(p=0.113, p=0.159$ and $p=0.182, p=0.955$, respectively, Table II). Similarly, the mean pre- and postoperative F0, jitter, shimmer and NHR values did not differ in group II $(p=0.2, p=0.613, p=0.175$ and $p=0.186$, respectively, Table I). In group III however, the differences between the mean pre- and postoperatively measured F0, jitter and NHR values were not statistically significant $(p=0.104, p=0.27$ and $p=0.416$ respectively $)$. On the other hand, postoperative shimmer values were lower than those measured preoperatively with statistically significance $(p=0.003$, Table I). The mean preoperative and postoperative formant frequencies (F1, F2, F3, and F4) were found to be statistically similar in all three groups

\section{DISCUSSION}

In this study, patients with severe septum deviation, undergoing septoplasty, showed significant betterment in voice but no significant change was observed in patients with mild to moderate septum deviation.

Sound is produced chiefly in the larynx and reaches its distinctive throughout the upper respiratory tract. ${ }^{14}$ Thus, any surgical interventions on pharynx, oral or nasal cavity may alter the layout or dimensions of the vocal tract and may consequently affect voice quality. ${ }^{15-17}$ For this reason, it may be necessary to evaluate the effects of surgical procedures targeting not only the larynx, but also the upper airway on voice quality.

VHI-30 is a validated questionnaire developed to evaluate the psychosocial consequences of voice disorders on individuals. ${ }^{13}$ In the previous studies in which VHI-30 was used to evaluate the subjective effects of septoplasty on voice, it was reported that there was a decrease in scores that could be interpreted as an improvement in the postoperative period. ${ }^{5,8,18}$ In a study examining the effects of septoplasty on voice performance, a significant decrease in VHI-30 scores was observed in the postoperative period in patients with severe septum deviation. ${ }^{8}$ Similarly, another study showed a decrease in VHI-30 scores in the postoperative period, but this decrease was not significant. ${ }^{18}$ In the study by Apaydın et al., in which the effects of septoplasty operation on sound were evaluated in patients showing betterment with acoustic rhinometry and rhinomanometry, it was reported that $\mathrm{VHI}$ scores were significantly improved. ${ }^{5}$ The present study, significant decrease in VHI-30 scores was found in the group with severe septum deviation, but no significant change was observed in VHI-30 scores in patients with mild and moderate septum deviation after septoplasty.

The fundamental frequency F0 is the vibration ratio of the vocal folds and one of the objective parameters of voice. There are conflicting results in the literature on whether septoplasty affects F0, or not. ${ }^{5,18}$ Mora et al. found a statistically significant decrease in objective parameters of voice, including F0, after septoplasty; and suggested that septoplasty improved the voice. ${ }^{18}$ In the same study, it was reported that the decrease in the pitch of the voice would generally reduce the resonance and result in a decrease in the nasal resonance values; and as a result, septoplasty was interpreted as a surgical procedure with the potential to improve the voice quality. ${ }^{18} \mathrm{~F} 0$ reflects the resonance characteristics of the supralaryngeal vocal tract, which is associated with tongue articulation and localisation. ${ }^{19}$ From this point of view, it can be predicted that F0 should not be affected in surgical interventions of the nasal cavity. In a study examining the effects of septoplasty on voice performance, the effectiveness of the operation was evaluated objectively and no substantial dissimilarity was found between pre- and postoperative mean FO values, ${ }^{5}$ which was also the case with our study. In our study, no substantial dissimilarity was found between the pre- and postoperative mean F0 values in the three groups. This finding was interpreted that the degree of septum deviation is not an effective factor on $\mathrm{F} 0$ and that septoplasty procedure does not alter the fundamental frequency of the voice.

Former studies examining the effects of septoplasty operation on the objective parameters of sound other than F0 also have reported conflicting results. ${ }^{4,8}$ In the study by Koc et al. in which the effects of septoplasty on voice was assessed, postoperative F0, jitter and shimmer values were found to be unaltered when compared to the pre-operative values. ${ }^{4}$ Atan et al. examined their patients in two groups according to their septum deviation degree as mild and severe and found that shimmer values were reduced after surgery, which suggests septoplasty may improve the sound in subjects with severe deviation. ${ }^{8}$ In the present study, a statistically significant decrease in shimmer value was detected in group III (i.e., in the group with severe septum deviation). No significant changes were observed in the objective sound parameters except shimmer in group III and in all sound parameters in groups I and II (i.e., patients with mild and moderate septum deviation). These findings suggest that septoplasty has a positive effect on the voice in patients with 
severe septum deviation, but not with mild and moderate septum deviation.

The resonance of the vocal tract is referred to as formant. ${ }^{20}$ Formants are determined by the size and shape of the oral, nasal, and pharyngeal cavities that form the acoustic area of the vocal tract. ${ }^{15}$ It is, therefore, possible that surgical procedures on the upper respiratory tract may alter the nasal resonance. It is suggested that the enlarged nasal cavity after surgery can increase the amplitude of the nasal formants by making a general decrease in acoustic damping. Behrman et al. ${ }^{15}$ reported in patients undergoing upper respiratory tract surgery (including septoplasty) that formant amplitudes of the nasal consonants $(/ \mathrm{m}, \mathrm{n} /)$ showed a significant increase when compared to the preoperative period. Gulec et al. reported in their prospective controlled study, ${ }^{7}$ in which they examined the effects of septoplasty on voice quality, that no substantial dissimilarity difference between pre- and postoperative formant frequencies was present, and suggested that the conflicting previous reports might be related to wound healing and variations in postoperative evaluation times. In this research, no statistical difference was discovered between the formant frequencies measured preoperatively and at the third postoperative month.

Previous studies on the subject have used varying approaches for grading the severity of septum deviation, relying on subjective rather than strict criteria. In addition, in only a portion of the studies, the effectiveness of septoplasty has been evaluated by acoustic rhinometry. Although there is no commonly used classification system for septum deviation that has been agreed upon, in order to avoid any conflicting results that may arise from severity classification, the patients' grouping was based on the system defined by Vidigal et al. ${ }^{9}$ The absence of a control group and an objective evaluation of the septoplasty efficacy were the main limitations of this study.

\section{CONCLUSION}

Septoplasty is a surgical procedure that has a positive effect on the voice in patients with severe septum deviation. More comprehensive studies, that eliminate the aforementioned deficiencies with a practical classification of septum deviation, will contribute to the literature.

\section{ETHICAL APPROVAL:}

Ethics Committee approval was received for this study from the Ethics Committee of University of Health Sciences, Ankara Numune Training and Research Hospital (Number:E-18-2296, November 1, 2018).

\section{PATIENTS' CONSENT:}

Informed consents were obtained from all individual participants included in the study.

\section{CONFLICT OF INTEREST:}

Authors declared no conflict of interest.

\section{AUTHORS' CONTRIBUTION:}

SEK: Contributed to the study conception and design, analysis and interpretation of data, drafting of manuscript, critical revision.

KMÖ: Contributed to the study conception and design, acquisition of data, drafting of manuscript.

Al: Contributed to the analysis and interpretation of data, drafting of manuscript, critical revision.

MAÇ: Contributed to the study conception and design, analysis and interpretation of data, drafting of manuscript. MÖ: Contributed to the study conception and design, analysis and interpretation of data, critical revision.

HHD: Contributed to the acquisition of data, drafting of manuscript, critical revision.

\section{REFERENCES}

1. Fettman N, Sanford T, Sindwani R. Surgical management of the deviated septum: techniques in septoplasty. Otolaryngol Clin North Am 2009; 42:241-52.

2. Brain D. The nasal septum. In: Scott-Brown WG, Stephens D, Kerr AG, eds. Scott-Brown's otolaryngology. $6^{\text {th }}$ ed. Oxford Butterרworth-Heinemann 1997; 1-27.

3. Muhammad IA, Nabil-ur Rahman. Complications of the surgery for deviated nasal septum. J Coll Physicians Surg Pak 2003; 13:565-8.

4. Ozbal Koc EA, Koc B, Ercan I, Kocak I, Tadihan E, Turgut S. Effects of septoplasty on speech and voice. J Voice 2014; 28: 393.e11-5.

5. Apaydın E, İkincioğulları A, Çolak M, Atan D, Ensari S, Dere HH. The voice performance after septoplasty with surgical efficacy demonstrated through acoustic rhinometry and rhinomanometry. J Voice 2019; 18:30531-9.

6. Karakurt SE, Cetin MA, Yamur AR, Ikinciogullari A, Ensari S, Dere $\mathrm{HH}$. Is adenotonsillar size a significant factor on voice in children undergoing adenotonsillectomy? J Coll Physicians Surg Pak 2019; 29:524-7.

7. Gulec S, Kulahli I, Sahin MI, Kokoğlu K, Gunes MS, Avci D, et al. Effect of septoplasty on voice quality: A prospective-controlled trial. Clin Exp Otorhinolaryngol 2016; 9:238-43.

8. Atan D, Özcan KM, Gürbüz AB, Dere $H$. The effect of septoplasty on voice performance in patients with severe and mild nasal septal deviation. J Craniofac Surg 2016; 27:1162-4.

9. De Aguiar Vidigal T, Martinho Haddad FL, Gregório LC, Poyares D, Tufik S, Azeredo Bittencourt LR. Subjective, anatomical, and functional nasal evaluation of patients with obstructive sleep apnea syndrome. Sleep Breath 2013; 17:427-33.

10. Mladina $\mathrm{R}$. The role of maxillar morphology in the development of pathological septal deformities. Rhinology 1987; 25:199-205.

11. Guyuron B, Uzzo CD, Scull H. A practical classification of septonasal deviation and an effective guide to septal surgery. Plast Reconstr Surg 1999; 104:2202-9.

12. Stewart MG, Witsell DL, Smith TL, Weaver EM, Yueh B, Hannley MT. Development and validation of the nasal obstruction symptom evaluation (nose) scale. Otolaryngol Head Neck Surg 2004; 130:157-63. 
13. Jacobson BH, Johnson A, Grywalski C, Silbergleit A, Jacobson G, Benninger MS, et al. The voice handicap index (VHI): Development and validation. Am J Speech Lang Pathol 1997; 6:66-70.

14. Atan D, Apaydın E, Özcan KM, İkincioğulları A, Çetin MA, Dere H. Does tonsillectomy affect voice in early or late postoperative periods in adults? J Voice 2017; 31:131.e5-131.e8.

15. Behrman A, Shikowitz MJ, Dailey S. The effect of upper airway surgery on voice. Otolaryngol Head Neck Surg 2002; 127: 36-42.

16. Warren DW, Dalston RM, Mayo R. Hypernasality and velopharyngeal impairment. Cleft Palate Craniofac J 1994; 31: 257-62.
17. Greene JS, Zipfel TE, Harlor M. The effect of uvulopalatopharyngoplasty on the nasality of voice. $J$ Voice 2004; 18: 423-30.

18. Mora R, Jankowska B, Dellepiane M, Mora F, Crippa B, Salami A. Acoustic features of voice after septoplasty. Med Sci Monit 2009; 15:CR269-73.

19. Salami A, Jankowska B, Dellepiane M, Crippa B, Mora R. The impact of tonsillectomy with or without adenoidectomy on speech and voice. Int J Pediatr Otorhinolaryngol 2008; 72 : 1377-84.

20. Borden GJ, Harris KS, Raphael LJ. Speech science primer: Physiology, acoustics, and perception of speech. $3^{\text {rd }}$ ed. Baltimore: Williams \& Wilkins 1994; 95-114. 